\title{
Prinsip-Prinsip Perjanjian Muamalat dalam Hukum Perbankan Syariah di Indonesia
}

\section{Faisal ${ }^{1}$}

Pembantu Dekan Bidang Kemahasiswaan Fakultas Hukum Universitas Malikussaleh Ketua Pusat Studi Hukum dan Pemerintahan Lhokseumawe

faichal_fh@yahoo.co.id

\begin{abstract}
According to the practice of Islamic banking principles, a bank should have muamalat agreement including the principle of deposit or deposits (depository/al-wadi'ah), the principle of profit sharing (profit-sharing), purchase (sale and purchase), leases (operational and financial lease lease), and services (fee-based services). Legal agreement adheres to several principles, including the principle of the freedom of an agreement (the sense of autonomy), the principle of adjustments will, and the principle of trust. In addition, there is also the principle of binding force, the principle of legal equality, the principle of balance, the principle of legal certainty, moral principles, merit principle, and the principle of habit.
\end{abstract}

\section{Keywords:}

Principles, Treaty of Muamalat, Islamic Banking

\begin{abstract}
Abstrak
Di dalam praktik perbankan syariah mempunyai prinsip-prinsip perjanjian muamalat antara lain prinsip titipan atau simpanan (depository/al-wadi'ah), prinsip bagi hasil (profit-sharing), jual beli (sale and purchase), sewa (operational lease and financial lease), dan jasa (fee-based services). Hukum perjanjian menganut beberapa asas, di antaranya asas kebebasan mengadakan perjanjian (arti otonomi), asas konsensualisme (penyesuaian kehendak), dan asas kepercayaan. Selain itu, ada juga asas kekuatan mengikat, asas persamaan hukum, asas keseimbangan, asas kepastian hukum, asas moral, asas kepatutan, dan asas kebiasaan.
\end{abstract}

\section{Kata Kunci:}

Prinsip, Perjanjian Muamalat, Perbankan Syariah 


\section{A. PENDAHULUAN}

\begin{abstract}
Pasal 33 ayat (1) Undang-
Undang Dasar (UUD) 1945, menyatakan bahwa perekonomian disusun sebagai usaha bersama berdasarkan asas kekeluargaan. Lebih lanjut, pada Pasal 33 ayat (4) menyatakan bahwa perekonomian nasional diselenggarakan berdasarkan demokrasi ekonomi dengan prinsip kebersamaan, efisiensi berkeadilan, berkelanjutan, berwawasan lingkungan, kemandirian, serta dengan menjaga keseimbangan kemajuan dan kesatuan ekonomi nasional. Kedua pasal tersebut menjelaskan bahwa prinsip perekonomian Indonesia merupakan hasil dari kegiatan usaha bersama dengan menganut asas kekeluargaan.
\end{abstract}

\footnotetext{
1"Sesungguhnya orang-orang mu'min adalah bersaudara karena itu damaikanlah antara kedua saudaramu dan bertaqwalah kepada Allah supaya kamu mendapat rahmat." (QS. Al-Hujarat:10)

2“.. janganlah kamu menjadi orang yang musyrik, yaitu orang yang menjadikan agama berpecah-belah, dan masingmasing kelompok berbangga-bangga dengan kelompoknya" (QS Ar-Ruum:3132).

3“..dan berpeganglah kamu semuanya kepada tali (agama)Allah dan janganlah kamu bercerai berai" (QS Ali Imran: 103).

4"Apakah mereka yang membagi-bagi rahmat Tuhanmu? Kami yang membagi antara mereka penghidupan mereka dalam kehidupan dunia ini. Dan Kami telah
}

Islam mengedepankan nilainilai kebersamaan dalam melakukan kegiatan usaha. Nilai-nilai kebersamaan tersebut terdapat dalam ayatayat Alquran. Alquran mengandung anjuran kepada umat manusia untuk selalu dalam kebersamaan, baik kebersamaan dalam bentuk mewujudkan kebaikan (kedamaian), ${ }^{1}$ maupun kebersamaan dalam bentuk tidak membangga-banggakan terhadap yang lain, ${ }^{2}$ kebersamaan juga dalam bentuk tidak melakukan perpecahan, ${ }^{3}$ dan kebersamaan dalam bentuk saling membantu terhadap sesamanya. ${ }^{4}$ Begitu juga dalam AsSunnah diterangkan bahwa kebersamaan itu dapat mendatangkan kebaikan dan menghilangkan perpecahan. ${ }^{5}$ Lebih lanjut, diterangkan

meninggikan sebagian mereka atas sebagian yang lain beberapa tingkat, agar sebagian mereka dapat mempergunakan sebagian yang lain, dan rahmat Tuhanmu lebih baik dari apa yang mereka kumpulkan" (QS. Al-Zukhruf: 32).

5“...Wajib atas kalian untuk bersama dengan al-jamaah dan berhati-hatilah kalian dari perpecahan. Sesungguhnya setan bersama orang yang sendirian, sedangkan dari orang yang berdua dia lebih jauh. Barangsiapa yang menginginkan tengah-tengahnya (yang terbaiknya) surga maka hendaklah dia bersama jamaah. Barangsiapa yang kebaikan-kebaikannya menggembirakan dia dan kejelekan-kejelekannya menyusah- 
bahwa agama Allah (addin) memberikan tempat bagi orang-orang yang selalu berada dalam kebersamaan (berjamaah). ${ }^{6}$ Dengan demikian, kebersamaan merupakan cerminan nilai-nilai yang terdapat dalam Alquran dan As-Sunnah, sehingga kegiatan usaha yang didasarkan pada kebersamaan tersebut lebih diutamakan atau lebih ditekankan dalam Islam.

Hikmah di balik kebersamaan adalah mendapatkan rahmat Allah karena Allah telah menjanjikan orangorang yang selalu dalam kebersamaan diberikan tempat yang baik di sisiNya.Artinya, kebersamaan merupakan titah Allah untuk melakukan kebajikan dalam mengemban amanah Allah SWT di permukaan bumi.

Syariah Islam merupakan aturan yang komprehensif dan universal. ${ }^{7}$ Komprehensif berarti syariah Islam dapat mengatur umat

kan dia, maka dia adalah seorang mukmin." (HR. At-Tirmidzi).

${ }^{6}$ Diriwayatkan dari Ibnu Mas'ud ra bahwa ia berkata "Wahai manusia, wajib atas kalian untuk taat dan tetap berasama jamaah, karena itulah tali Allah yang sangat kuat. Ketahuilah! apa yang tidak kalian sukai bersama jamaah lebih baik daripada apa yang kalian sukai bersama perpecahan" (As-Syari'ah karya Al-Jurri manusia dalam pelbagai bidang, termasuk di bidang ibadah 'ubudiyah/mahdhah dan ibadah muamalah. Ibadah 'ubudiyah adalah ibadah yang dikerjakan atas segala sesuatu karena diperintahkan oleh Allah SWT. Adapun bidang ibadah muamalah adalah perbuatan yang dilakukan oleh setiap muslimyang mempunyai kebebasan untuk menentukannya, sepanjang tidak bertentangan dengan aturan-aturan yang telah ditetapkan dalam Alquran dan As-Sunnah. Hal tersebut seperti dinyatakan oleh S.J. Shahidi, "Islam purported to address not only the Ubudiyyat (Godly issues) but also it claimed the ultimate authority in muamelat (worldly issues)".8

Universal mempunyai pengertian bahwa syariat Islam di bidang muamalat dapat diterapkan dalam setiap saat. Selain itu, syariat Islam mempunyai cakupanluas dan fleksibel, yang ditujukan kepada seluruh umat

rahimahullahu, hlm. 23-24 Cet Darussalam, Riyadh).

${ }^{7}$ Muhammad Syafi'i Antonio, 2001, Bank Syari'ah: Dari Teori ke Praktik, Gema Insani Press, Jakarta, hlm. 4.

${ }^{8}$ Nima Mersadi Tabari, 2010, "Islamic Finance and The Modern World: The Legal Principles Governing Islamic Finance in International Trade", Company Lawyer, Comp. Law. 31(8), 249-254, hlm. 249. 
manusia tanpa membeda-bedakan antara muslim dengan non-muslim. Lebih lanjut, Imtiaz Pervez menyatakan seperti di bawah ini. ${ }^{9}$

[Islam] is a comprehensive way of life, religious and secular; it is a set of beliefs and a way of worship; it is a vast and integrated system of laws; it is a culture and a civilization; it is an economic system and commercial norm; it is a polity and a method of governance; it is a society and a family conduct; it prescribes for inheritance and divorce, dress and etiquette, food and personal hygiene. It is spiritual and human totality; thus worldly and other-worldly.

Sehubungan dengan pengaturan ibadah muamalah, dalam kaidah fikih dinyatakan bahwa "alashlu fil mu'amalatil ibahah illa anyadulla dalilun 'ala tahrimiha."10 Maksudnya, segala sesuatu perbuatan yang berkaitan dengan bidang muamalah pada dasarnya boleh dilakukan, kecuali ada dalil yang mengharamkannya. Berdasarkan kaidah tersebut, setiap orang mempunyai kebebasan dalam menjalankan kegiatan usaha di bidang muamalah dengan batasan-batasan

9J. Michael Taylor, 2003, "Islamic Banking-The Feasibility of Establishing an Islamic Bank in The United States", American Business Law Journal, 40 Am. Bus. L.J. 385, Winter, hlm. 387.

\footnotetext{
${ }^{10}$ Lihat, Himpunan Fatwa Dewan Syariah Nasional Untuk Lembaga Keuangan Syariah. 2001, Dewan Syariah Nasional-Majelis Ulama Indonesia dan Bank Indonesia.
}

yang telah ditentukan dalam syariat Islam.

\section{B. IDENTIFIKASI MASALAH}

$$
\text { Pada penelitian ini }
$$
akandilakukan kajian lebih lanjut dengan permasalahan pokok, mencari tahu bagaimanakah prinsip-prinsip perjanjian muamalah dalam hukum perbankan Syariah di Indonesia.

\section{METODE PENELITIAN}

\section{Jenis dan Spesifikasi Penelitian}

Penelitian ini merupakan penelitian hukum normatif yang bersifat deskriptif analitis. Sifat deskriptif analitis dimaksudkan supaya dari hasil penelitian ini dapat diperoleh gambaran mengenai kebenaran hukum apa adanya melalui analisis secara mendalam. Hal ini sesuai dengan maksud dari penelitian hukum yaitu mencari kebenaran hukum ${ }^{11}$ yang terdapat dalam hukum positif.12 Lebih lanjut, kajian tentang hukum positif ini meliputi tiga bidang

\footnotetext{
11Menurut sifat Kebenaran hukum yang diungkapkan dalam penelitian ini termasuk kebenaran hukum kualitatif, karena mengungkapkan kesesuaian suatu ketentuan hukum yang menetapkan prasyarat kualitas tertentu yang harus dipenuhi, lihat F. Sugeng Istanto, 2007, Penelitian Hukum, Ganda, Yogyakarta, hlm. 47.
}

${ }^{12} \mathrm{~F}$. Sugeng Istanto, Ibid.,hlm. 30. 
kajian, yaitu kajian mengenai isi, penerapan, dan pembentukan hukum positif. ${ }^{13}$

\section{Sumber Data dan Alat Pengumpulan Data}

Data yang digunakan dalam penelitian ini adalah data sekunder sebagai data utama, yaitu penelusuran data sekunder dilakukan di perpustakaan dengan tujuan mendapatkan bahan hukum berupa norma atau kaidah yang terdiri atas asas-asas hukum dan nilai-nilai hukum.Data sekunder diperoleh dari bahan hukum primer, sekunder, dan tertier.

1). Bahan hukum primer, adalah ketentuan norma-norma dasar yang berkaitan dengan prinsipprinsip perjanjian muamalah dalam perbankan syariah di Indonesiayang diatur melalui hukum positif mau pun yang terdapat dalam Islam yang sudah dipositifisasi. Jadi, bahan hukum primer ini merupakan bahanbahan hukum yang mengikat.14 Bahan hukum primer terdiri atas

${ }^{13} \mathrm{~F}$. Sugeng Istanto, Ibid.,hlm. 31.

${ }^{14}$ Soerjono Soekanto, 2007, Pengantar Penelitian Hukum, Universitas Indonesia Press, Jakarta, hlm. 52. pelbagai peraturan perundangan sampai dengan Surat Edaran Bank Indonesia yang berkaitan dengan perjanjian muamalah dalam perbankan syariah di Indonesia.

2). Bahan hukum sekunder yang digunakan dalam penelitian ini adalah hasil-hasil penelitian dan pemikiran para ahli berkaitan dengan prinsip perjanjian Islam, perjanjian jual beli pada umumnya, dan jual beli. Bahan hukum sekunder ini memberikan penjelasan mengenai bahan hukum primer, ${ }^{15}$ yang terdiri atas pelbagai bahan kepustakaan mengenai prinsip perjanjian dalam Islam, hasil-hasil penelitian mengenai muamalah, makalah, dan artikel ilmiah mengenai perjanjian muamalah pada umumnya.

3). Bahan hukum tertier yaitu bahan yang memberikan petunjuk maupun penjelasan terhadap bahan hukum primer dan sekunder,16 yang terdiri atas beberapa kamus yaitu Kamus

${ }^{15}$ Soerjono Soekanto, Ibid., hlm. 52.

${ }^{16}$ Soerjono Soekanto dan Sri Mamudji, 1995, Penelitian Hukum Normatif: Suatu Tinjauan Singkat, RajaGrafindo Persada, Jakarta, hlm. 14. 
Besar Bahasa Indonesia (KBBI), Kamus Indonesia-Belanda [Indonesisch-Nederlands Woordenboek], Kamus Hukum, Kamus Arab-Indonesia.

\section{Analisis Data}

\begin{tabular}{ccc}
\multicolumn{2}{c}{ Sebelum data dianalisis } \\
terlebih dahulu dilakukan
\end{tabular} pengorganisasian data terhadap data sekunder yang telah dikumpulkan melalui studi dokumen. Selanjutnya data tersebut dikumpulkan, dikelompokkan kedalam klasifikasi tertentu terkait rumusan masalah, dan dicatat secara sistematis untuk memudahkan dalam proses analisis. Analisis yang dipergunakan dalam penelitian adalah analisis kualitatif secara yuridis normative.

\section{PRINSIP-PRINSIP PERJANJIAN MUAMALAT DALAM HUKUM PERBANKAN SYARIAH DI INDONESIA}

Di dalam syariah Islam (hukum Islam) telah diletakkan dasar-dasar

${ }^{17}$ Syariah dalam arti luas adalah ajaran Islam, didalamnya terdapat akidah dan syariah (dalam arti sempit). Syariah dalam arti sempit antara lain: akhlak, ibadat, muamalah (dalam arti luas). Muamalah dalam arti luas adalah hukum muamalat (dalam arti sempit), hukum keluarga, hukum pidana, hukum konstitusi, hukum internasional dan lain-lain. Lihat Samsul Anwar, 2006, Bahan Kuliah S3 Ekonomi Islam, UIN Sunan Kalijaga, Yogyakarta. ekonomi supaya umat Islam dapat melakukan pelbagai aktivitas dalam kehidupan masyarakat, khususnya dalam perjanjian muamalat yang terdapat dalam hukum perbankan syariah di Indonesia harus dijalankan sesuai dengan prinsip-prinsip syariah. ${ }^{17}$ Adapun pengertian prinsip atau asas secara etimologis adalah kebenaran yang menjadi pokok dasar berpikir dan bertindak. ${ }^{18}$ Bellefroid berpendapat bahwa asas hukum adalah norma dasar yang dijabarkan dari hukum positif dan yang oleh ilmu hukum tidak dianggap berasal dari aturan-aturan yang lebih umum. Asas hukum umum itu merupakan pengendapan hukum positif dalam suatu masyarakat. ${ }^{19}$

Menurut Sholten, yang dimaksud dengan asas hukum adalah kecenderungan-kecenderungan yang diisyaratkan oleh pandangan kesusilaan pada hukum, merupakan sifat-sifat umum dengan segala

18Anonimus, 1990, Kamus Besar Bahasa Indonesia, Cet. Ketiga, Departemen Pendidikan dan Kebudayaan, Balai Pustaka, Jakarta, hlm. 701.

${ }^{19}$ Notohamidjojo dalam Sudikno Mertokusumo, 2001, Penemuan Hukum; Sebuah Pengantar, Liberty, Yogyakarta, hlm. 5 
keterbatasannya sebagai pembawaan yang umum itu tetapi yang tidak boleh tidak harus ada. ${ }^{20}$ Oleh karena itu, prinsip syariah dapat diartikan sebagai suatu kebenaran yang dijadikan acuan untuk melakukan tindakan sesuai hukum Islam. Abd.ElRehim Mohamed Al-Kashif menyatakan.

"An "Islamic financial institution" is the institution offering Shari'ah (Islamic law) compliant financial services and products by using financial intermediation based on the principles of Islam. In Islam, Islamic rules and principles cover all aspects of life: religious, political, social and economic issues. Islamic finance, as a segment of Islamic economy, is governed by Islamic law. The main sources of deducing an Islamic law are the Qur'an, Sunna (sayings and deeds of the Prophet Mohammed), Ijma' (consensus) and Qiyas (analogy)".21

Prinsip ekonomi syariah yang kemudian digunakan dalam lembaga keuangan Islam, di dalamnya menawarkan pelbagai jasa dan produk sesuai dengan prinsip-prinsip Syariah. Prinsip syariah antara lain, prinsip perbankan non riba, prinsip perniagaan halal dan tidak haram, prinsip keridaan para pihak dalam

\footnotetext{
${ }^{20}$ Sudikno Mertokusumo, Ibd., hlm. 5

${ }^{21} \mathrm{Abd}$. El-Rehim Mohamed Al-Kashif, 2008, Islamic institutions offering financial services: the constructive role and implications of their modes for efforts to combat serious financial crime, Comp. Law. 2008, 29(7), 218-224, Company Lawyer, hlm. 218.
}

berkontrak, dan prinsip pengurusan dana yang amanah, jujur, dan bertanggung jawab. ${ }^{22}$ Prinsip-prinsip tersebut itulah yang kemudian dikenal dengan istilah prinsip ekonomi syariah.

Adapun pembedakan prinsip ekonomi syariah yang diterapkan dalam pembiayaan Islam dengan pembiayaan konvensional (bunga), dapat dijelaskan dalam tabel berikut ini.

\section{Perbedaan Pembiayaan Islam dengan Konvensional $^{23}$}

\begin{tabular}{|c|c|c|}
\hline No & Islamic finance & Conventional finance \\
\hline 1 & $\begin{array}{l}\text { Sources of principles: } \\
\text { Based on guidelines from } \\
\text { the Qur'an and Sunnah } \\
\text { and developed with } \\
\text { ijtihad, the reasoning } \\
\text { and efforts of experts and } \\
\text { scholars }\end{array}$ & $\begin{array}{l}\text { Sources of principles: } \\
\text { Purely man-made. } \\
\text { Conventional financial } \\
\text { systems are basically } \\
\text { secular in nature and } \\
\text { religion is totally } \\
\text { separate from trade } \\
\text { and commerce. }\end{array}$ \\
\hline 2 & $\begin{array}{l}\text { Nature of contract: } \\
\text { The legal relationship } \\
\text { cannot be usurious or } \\
\text { interest-based and } \\
\text { should involve elements } \\
\text { of profitand-risk sharing, } \\
\text { partnership or } \\
\text { investment. In loans, the } \\
\text { interest rate should not } \\
\text { be stipulated in the } \\
\text { agreement. }\end{array}$ & $\begin{array}{l}\text { Nature of contract: } \\
\text { The legal relationship is } \\
\text { typically one of } \\
\text { creditor-borrower in } \\
\text { which the creditor is } \\
\text { assured of } \\
\text { predetermined usury or } \\
\text { interest }\end{array}$ \\
\hline
\end{tabular}

${ }^{22}$ Jafril Khalil, 2002, Prinsip Syari'ah dalam Perbankan, Jurnal Hukum Bisnis, Vol 20, Agustus-September, Yayasan Pengembangan Hukum Bisnis, Jakarta, hlm. 47.

${ }^{23}$ Mohd Yazid Bin Zul Kepli, 2012, Islamic Finance in Hong Kong, 42 HKLJ 809, Hong Kong Law Journal, hlm. 5-6. 


\begin{tabular}{|c|c|c|}
\hline 3 & $\begin{array}{l}\text { Zakat: } \\
\text { Islamic financial } \\
\text { institutions must pay } \\
\text { zakator Islamictax. They } \\
\text { sometimes also act as } \\
\text { zakat collection centres. }\end{array}$ & $\begin{array}{l}\text { Zakat: } \\
\text { It is not compulsory to } \\
\text { pay zakat. }\end{array}$ \\
\hline 4 & $\begin{array}{l}\text { Purpose: } \\
\text { Maximisation of profit in } \\
\text { accordance with Islamic } \\
\text { principles }\end{array}$ & $\begin{array}{l}\text { Purpose: } \\
\text { Maximisation of profit. }\end{array}$ \\
\hline 5 & $\begin{array}{l}\text { Default and penalties: } \\
\text { Islamic financial } \\
\text { institutions cannot } \\
\text { accept usury and } \\
\text { penalties are often } \\
\text { strictly interpreted as } \\
\text { constituting usury if } \\
\text { taken. Therefore, in cases } \\
\text { of default, penalties go to } \\
\text { charity and no party } \\
\text { benefits from the default. }\end{array}$ & $\begin{array}{l}\text { Default and penalties: } \\
\text { It is common to charge } \\
\text { penalties in cases of } \\
\text { default. These penalties } \\
\text { can be a lucrative } \\
\text { source of income, e.g. } \\
\text { for credit card } \\
\text { companies, with the } \\
\text { creditor benefitting } \\
\text { when the borrower } \\
\text { defaults (via interest). }\end{array}$ \\
\hline 6 & $\begin{array}{l}\text { Relationship to } \\
\text { productivity: } \\
\text { Growth and productivity } \\
\text { are vital, and because the } \\
\text { main objective is profit, } \\
\text { profit should be } \\
\text { generated from real } \\
\text { trade and commerce } \\
\text { while encouraging all } \\
\text { parties to experience } \\
\text { growth and productivity. }\end{array}$ & $\begin{array}{l}\text { Relationship to } \\
\text { productivity: } \\
\text { The creditor's main } \\
\text { concern is repayment of } \\
\text { the loan and interest. } \\
\text { Performance of the } \\
\text { borrower, e.g. a } \\
\text { business or company, is } \\
\text { not the primary } \\
\text { concern. }\end{array}$ \\
\hline 7 & $\begin{array}{l}\text { Nature of products: } \\
\text { Only shariah-compliant } \\
\text { products can be used. }\end{array}$ & $\begin{array}{l}\text { Nature of products: } \\
\text { All legal financial } \\
\text { products can be used }\end{array}$ \\
\hline 8 & $\begin{array}{l}\text { Selection of client: } \\
\text { The creditworthiness of } \\
\text { the client is considered, } \\
\text { but the main focus is the } \\
\text { feasibility and } \\
\text { profitability of the } \\
\text { project }\end{array}$ & $\begin{array}{l}\text { Selection of client: } \\
\text { The main focus is the } \\
\text { creditworthiness of the } \\
\text { client. }\end{array}$ \\
\hline 9 & $\begin{array}{l}\text { The nature of risk } \\
\text { allocation: } \\
\text { The concept should be } \\
\text { investment, risk sharing } \\
\text { or partnership, or } \\
\text { another permissible } \\
\text { contract. }\end{array}$ & $\begin{array}{l}\text { The nature of risk } \\
\text { allocation: } \\
\text { The concept is based on } \\
\text { risk transfer. }\end{array}$ \\
\hline
\end{tabular}

\begin{tabular}{|c|c|c|}
\hline 10 & $\begin{array}{l}\text { Profit Guarantee: } \\
\text { Guaranteeing any profit } \\
\text { or future income is often } \\
\text { prohibited. Deposits can } \\
\text { be guaranteed using } \\
\text { certain contracts such as } \\
\text { waadiah, but profit can } \\
\text { only be shared if it exists } \\
\text { and cannot be } \\
\text { guaranteed in advance. }\end{array}$ & $\begin{array}{l}\text { Profit/Interest } \\
\text { Guarantee: } \\
\text { Guaranteeing interest is } \\
\text { a } \quad \text { common } \\
\text { characteristic rinancial } \\
\text { conventional finations. } \\
\text { institution }\end{array}$ \\
\hline 11 & $\begin{array}{l}\text { Volatility: } \\
\text { While Islamic finance is } \\
\text { less volatile due to some } \\
\text { of its prohibitions on } \\
\text { speculative activities, it } \\
\text { can still be exposed to } \\
\text { asset and other bubbles. } \\
\text { Furthermore, because it } \\
\text { is exposed to } \\
\text { conventional monetary } \\
\text { systems, problems in such } \\
\text { conventional systems } \\
\text { have an effect on Islamic } \\
\text { finance. }\end{array}$ & $\begin{array}{l}\text { Volatility: } \\
\text { Conventional finance } \\
\text { can be highly volatile } \\
\text { and fragile as a result of } \\
\text { excessive speculative } \\
\text { activities. }\end{array}$ \\
\hline \multicolumn{3}{|c|}{ Prinsip ekonomi syariah dapat } \\
\hline \multirow{2}{*}{\multicolumn{3}{|c|}{$\begin{array}{l}\text { diterapkan dalam praktik kehidupan } \\
\text { sehari-hari bagi individu, keluarga, }\end{array}$}} \\
\hline & & \\
\hline \multicolumn{3}{|c|}{ tersebut dilakukan untuk } \\
\hline \multicolumn{3}{|c|}{ mengorganisasikan faktor produksi, } \\
\hline \multicolumn{3}{|c|}{ distribusi, dan pemanfaatan barang } \\
\hline \multicolumn{3}{|c|}{ serta jasa yang akan dihasilkan agar } \\
\hline \multicolumn{3}{|c|}{ tunduk dalam aturan-aturan Islam } \\
\hline \multicolumn{3}{|c|}{ (sunnatullah).24 Kegiatan usaha yang } \\
\hline \multicolumn{3}{|c|}{ dilakukan oleh bank syariah mengacu } \\
\hline \multicolumn{3}{|c|}{ pada prinsip bagi hasil (profit and loss } \\
\hline \multicolumn{3}{|c|}{ sharing) dengan } \\
\hline \multicolumn{3}{|c|}{ setaraan } \\
\hline \multicolumn{3}{|c|}{ (fairness), } \\
\hline \multicolumn{3}{|c|}{ (transparency). Lebih } \\
\hline
\end{tabular}

${ }^{24}$ Suhrawardi K. Lubis, 2000, Hukum Ekonomi Islam, Sinar Grafika, Jakarta, hlm. 14. 
pengembangan perbankan syariah ${ }^{25}$ menyatakan bahwa perbankan syariah secara makro mempunyai misi ke depan. Misi tersebut adalah pembinaan manajemen keuangan masyarakat (proses tarbiyah), pengembangan kompetisi yang sehat, pengembangan lembaga zakat, dan pembentukan ukhuwah (networking) dengan lembaga keuangan Islam lainnya.

Selain itu, prinsip syariah mendukung kewirausahaan, membagi risiko dan keterlibatan orang miskin untuk ikut bersama. Rahul Dhumale dan Amela Sapcanin menyatakan. "The principles of Shari'a advocate entrepreneurship and risk sharing and believe that the poor should take part in such activities", 26

Adapun di dalam literatur lain disebutkan bahwa ada lima prinsip lembaga keuangan Islam. ${ }^{27}$ Pertama, prinsip ta'awun, yaitu prinsip saling membantu dalam meningkatkan taraf hidup melalui mekanisme kerja

\footnotetext{
${ }^{25}$ Fathurrahman Djamil, 2002, "Urgensi Undang-Undang Perbankan Syari'ah di Indonesia", Jurnal Hukum Bisnis, Vol 20, Agustus-September, Yayasan Pengembangan Hukum Bisnis, Jakarta, hlm. 41.

${ }^{26}$ Rahul Dhumale dan Amela Sapcanin dalam Betsy Walters, 2012, "Islamic
}

ekonomi dan bisnis. Kedua,prinsip tijarah, yaitu prinsip mencari laba dengan cara yang dibenarkan oleh syariat. Ketiga, prinsip menghindari iktinaz, yaitu prinsip tidak menahan uang berputar, sehingga dapat memberikan manfaat kepada masyarakat. Keempat, prinsip pelarangan riba, yaitu menghindari transaksi ekonomi dan bisnis dari unsur riba. Kelima, prinsip pembayaran zakat, yaitu lembaga keuangan Islam yang berfungsi sebagai lembaga keuangan syariah dan berfungsi sosial sebagai amil yang mengelola zakat.

Selain itu, sistem yang dianut dalam kegiatan usaha bank syariah adalah sistem terbuka (open system). Sistem tersebut sama seperti yang dianut dalam lingkungan hukum perjanjian perdata barat. Hukum tersebut menyatakan bahwa pada dasarnya semua produk jasa bank konvensional dapat dijadikan sebagai produk jasa bank syariah untuk dapat

Microfinance: Sustainable Poverty Alleviation for the Muslim Poor", 11 Conn. Pub. Int. L.J. 255, Connecticut Public Interest Law Journal, hlm. 265.

${ }^{27}$ Abdul Ghofur Anshori, 2006, Gadai Syariah di Indonesia: Implementasi dan Institusionalisasi, Cet. Pertama, Gadjah Mada Press, Yogyakarta, hlm. 86-87. 
dijual kepada masyarakat, dengan batasan-batasan syariah atau tidak bertentangan dengan prinsip syariah. ${ }^{28}$

Berdasarkan Pasal 1 butir (12), UU No. 21 Tahun 2008, yang dimaksud dengan prinsip syariah adalah prinsip hukum Islam dalam kegiatan perbankan berdasarkan fatwa yang dikeluarkan oleh lembaga yang memiliki kewenangan dalam penetapan fatwa di bidang syariah. Dengan prinsip tersebut, perbankan syariah dapat menjalankan kegiatan usaha dengan berpedoman pada fatwa yang telah ditetapkan oleh Dewan Syariah Nasional-Majelis Ulama Indonesia (DSN-MUI).

Berdasarkan uraian di atas, dapat disimpulkan bahwa prinsipprinsip ekonomi Islam secara umum yang terdapat dalam fikih maupun prinsip syariah yang telah digali berdasarkan ijtihat melalui fatwa dari DSN-MUI, bahkan asas-asas dalam hukum perdata secara umum yang tidak bertentangan dengan hukum Islam, sehingga dapat diterapkan

\footnotetext{
28Mardjono, 2000, Petunjuk Praktis: Menjalankan Syari'at Islam dalam Bermuamalah yang Sah Menurut Hukum Islam, Dewan Pimpinan Pusat Bulan Bintang, Jakarta, hlm. 20.
}

dalam perbankan syariah. Penerapan tersebut dapat dilakukan karena mengingat prinsip atau asas itu merupakan bersifat umum, sehingga dapat diterapkan dalam produk perbankan.Lebih lanjut, Sudikno Mertokusumo menyatakan bahwa asas hukum pada umumnya bersifat dinamis dan berkembang mengikuti kaidah hukumnya. Adapun kaidah hukum akan berubah mengikuti perkembangan masyarakat, sehingga mempengaruhi waktu dan tempat (historisch bestimmt). ${ }^{29}$

Walaupun pada umumnya asas hukum itu bersifat dinamis, tetapi menurut Sholten ada asas hukum yang bersifat universal yang berlaku kapan saja dan dimana saja serta tidak terpengaruh dengan waktu dan tempat. Sholten menyebut ada lima asas hukum universal, yaitu asas kepribadian, asas persekutuan, asas kesamaan, asas kewibawaan, dan asas pemisahan antara baik dan buruk. ${ }^{30}$ Dengan demikian, asas-asas hukum universal tersebut dapat dijadikan sebagai acuan bertindak dan

\footnotetext{
${ }^{29}$ Sudikno Mertokusumo, 2001, Penemuan Hukum; Suatu Pengantar, Liberti, Yogyakarta, hlm. 9.

${ }^{30}$ Scholten dalam Sudikno Mertokusumo, Ibid., hlm. 9.
} 


\begin{tabular}{|c|c|}
\hline berperilaku & kehidupan \\
\hline bermasyakat, & sehingga \\
\hline melahirkan & keseimbangan \\
\hline harmonisan & seperti yang $\mathrm{d}$ \\
\hline
\end{tabular}

Kegiatan usaha yang dijalankan oleh perbankan syariah didasarkan pada prinsip-prinsip syariah. Prinsip-prinsip syariah merupakan prinsip umum yang dapat diterapkan dalam bidang muamalat. Muamalat merupakan bentuk jamak dari muamalah yang artinya hubungan atau perlakuan. Oleh karena itu, muamalat dapat diartikan sebagai hubungan-hubungan antar individu atau badan hukum dengan individu lain atau badan hukum lain yang melibatkan benda secara langsung maupun secara tidak langsung. ${ }^{31}$ Muamalat dalam arti luas mengatur seluruh bidang kehidupan manusia, sedangkan muamalat dalam arti sempit mengatur bidang ekonomi Islam (badan hukum, hukum benda, perikatan, dan bisnis). Oleh karena itu, prinsip syariah secara umum merupakan prinsip muamalat yang

\footnotetext{
${ }^{31}$ Syamsul Anwar,Op. Cit.,

${ }^{32}$ Muhammad Amin Suma, Op. Cit., hlm. 18.
}

dapat diterapkan dalam pelbagai bidang.

Muamalat dalam konteks ekonomi Islam mempunyai prinsipprinsip perikatan, atau prinsip-prinsip perjanjian syariah. Prinsip-prinsip tersebut dapat diterapkan dalam prinsip jual beli, antara lain salam, murabahah, dan istishna'. Selain itu, prinsip-prinsip perjanjian syariah merupakan prinsip perjanjian (asasasas al-uqud) yang merupakan cerminan dari bentuk perjanjian ekonomi Islam, yakni sebagai berikut. ${ }^{32}$

Pertama, prinsip ridha'iyyah (kerelaan), yaitu prinsip yang digunakan dalam melakukan suatu perjanjian antara pihak bank syariah dengan nasabah yang didasarkan pada prinsip rela sama rela. Prinsip tersebut didasarkan pada ayat Alquran ${ }^{33}$ yang di dalamnya mengandung prinsip 'antaradhin/al-taradhi. Dengan demikian, semua bentuk perjanjian yang didalamnya terkandung unsur paksaan (ikrah) harus ditolak dan dinyatakan batal demi hukum. Unsurunsur tersebut antara lain unsur 
kebatilan (al-bathil), misalnya jual beli yang mengandung unsur pemaksaan (bay'ul mukrah).

Kedua, prinsip manfaat, yaitu suatu perjanjian antara bank syariah dengannasabah yang dilakukan dengan mempertimbangkan manfaat bagi para pihak yang terlibat didalamnya. Di dalam ajaran Islam, para pihak dilarang melakukan pelbagai bentuk perjanjian yang bersifat mudharat/mafsadat, misalnya jual beli barang-barang yang diharamkan serta melakukan jual beli terhadap barang yang tidak bermanfaat dan membahayakan.

Ketiga, prinsip keadilan, yaitu prinsip dalam perjanjian yang dibuat oleh pihak bank syariah dan nasabah yang diperlakukan secara adil. Hal tersebut merupakan perwujudan dari beberapa ayat Alquran yang menjunjung tinggi nilai keadilan dan anti kezaliman. ${ }^{34}$ Kezaliman mempunyai makna, yakni melakukan ekploitasi bagi perekonomian masyarakat, termasuk di dalamnya melakukan pembungaan uang (interest) dalam sistem pembiayaan dan perbankan. Lebih lanjut, Angelo M. Venardos menyatakan bahwa
"Interest, which is the kingpin of the modern banking and financial system, serves as a powerful tool of exploitation of one sector of society by another". 35

Keempat, prinsip saling menguntungkan, yaitu perjanjian yang dibuat antara pihak bank syariah dengan nasabah dapat menguntungkan semua pihak dan tidak merugikan pihak lain. Oleh karena itu, Islam melarang melakukan kegiatan usaha (mu'amalat) yang mengandung unsur penipuan (gharar), sehingga dapat merugikan pihak lain.

Perbankan syariah merupakan perbankan yang melakukan kegiatan usaha berdasarkan prinsip syariah. Prinsip syariah tersebut termasuk juga dalam pembuatan perjanjian antara bank syariah dengan nasabah. Prinsip syariah didasarkan pada prinsipprinsip perjanjian (asas-asas al-Uqud) yang telah diatur dalam hukum ekonomi Islam. Pengabaian terhadap prinsip-prinsip tersebut akan menyebabkan perjanjian batal demi 
hukum. Ringkasnya, semua produk yang dihasilkan menjadi haram. ${ }^{36}$

Hukum perjanjian menganut beberapa asas. Di antaranya adalah ${ }^{37}$ asas kebebasan mengadakan perjanjian (arti otonomi), asas konsensualisme (penyesuaian kehendak), dan asas kepercayaan. Selain itu, ada juga asas kekuatan mengikat, asas persamaan hukum, asas keseimbangan, asas kepastian hukum, asas moral, asas kepatutan, dan asas kebiasaan.

Berdasarkan beberapa asas perjanjian seperti disebut di atas, ada tiga asas yang menjadi tonggak hukum perjanjian dalam hukum perbankan.

Ketiga asas tersebut adalah asas konsensualisme, asas kebebasan berkontrak, dan asas kekuatan mengikat. Asas konsensualisme dilahirkan pada saat momentum awal terjadinya perjanjian, yaitu ketika para pihak mencapai puncak kesepakatannya. Adapun para pihak menentukan hak dan kewajiban serta

${ }^{36}$ Muhammad.Amin Suma, Op. Cit., hlm. 19.

37Mariam Darus Badrulzaman, 2001, KUH Perdata, Buku III, Hukum Perikatan dengan Penjelasan, Alumni, Bandung, hlm. 108.

${ }^{38}$ Tan Kamello, 2006, "Karakter Hukum Perdata dalam Fungsi Perbankan hal-hal lain yang menjadi substansi perjanjian, mereka telah memasuki ruang asas kebebasan berkontrak. Di dalam asas ini, para pihak dapat menentukan sendiri bentuk dan isi perjanjian secara bebas sepanjang dapat dipertanggungjawabkan. Tekanan dari salah satu pihak melalui ketidaksamaan dalam tawar-menawar (bargaining power) dapat mengakibatkan prestasi perjanjian tidak seimbang dan hal ini melanggar asas iustum pretium. $^{38}$ Perjanjian tersebut akan menjadi cacat dan dapat dibatalkan (vernietigbaar, voidable). Adanya persetujuan secara timbal balik terhadap bentuk dan isi perjanjian ditandai dengan adanya pembubuhan tanda tangan atau yang dapat dipersamakan dengan itu. Tanda tangan yang dibubuhkan para pihak menjadi pengakuan yang sah terhadap isi perjanjian. Akibatnya, hal tersebut akan mengikat kedua belah pihak dan mereka harus melaksanakannya dengan itikad baik (in good faith). ${ }^{39}$

melalui Hubungan antara Bank dengan Nasabah", Pidato Pengukuhan Jabatan Guru Besar Tetap dalam Bidang Ilmu Hukum Perdata, Fakultas Hukum, Universitas Sumatera Utara. hlm. 11

${ }^{39}$ Jonker Sihombing, 2008, Tanggung Jawab Yuridis Bankir atas Kredit Macet Nasabah, Alumni, Bandung, hlm. 54. 
Selain prinsip-prinsip perjanjian yang telah diuraikan di atas, di dalam praktik perbankan syariah juga mempunyai lima prinsip-prinsip dasar. Di antaranya adalah ${ }^{40}$ prinsip titipan atau simpanan (depository/alwadi'ah), prinsip bagi hasil (profitsharing), jual beli (sale and purchase), sewa (operational lease and financial lease), dan jasa (fee-based services).

Prinsip-prinsip tersebut dapat diimplimentasikan ke dalam produk perbankan syariah, yakni pada produk perhimpunan, penyaluran dana, dan jasa. Prinsip-prinsip tersebut di dalam konteks Indonesia telah dituangkan dalam fatwa DSN-MUI. Oleh karena itu, dengan berpedoman pada fatwa tersebut, lembaga keuangan yang ada dapat membuat skema produk yang tidak bertentangan dengan prinsip syariah. Fatwa DSN-MUI antara lain memberikan pedoman bagi lembaga perbankan, asuransi, pasar modal, reksa dana, dan lembaga keuangan lainnya.

Substansi fatwa DSN-MUI agar mempunyai kekuatan hukum

\footnotetext{
${ }^{40}$ M. Syafi'I Antonio, Op.Cit.,hlm. 83.

41Khotibul Umam, 2009, Hukum Ekonomi Islam; Dinamika dan Perkembangan di Indonesia, Instan Lib, Yogyakarta, hlm. 3.
}

mengikat, akan dilakukan positivisasi fatwa dalam peraturan perundangundangan. Antara lain dalam bentuk Peraturan Bank Indonesia (PBI) dan keputusan ketua Badan Pengawas Pasar Modal-Lembaga Keuangan (Bapepam-LK).41 Positifisasi fatwa DSN-MUI diperlukan harmonisasi dengan Peraturan Bank Indonesia (PBI) agar perbankan syariah dapat berjalan sesuai hukum positif di Indonesia. Tim Lindsey, menyatakan bahwa:

“...the state regulatory policy, calling for 'promoting and facilitating the formulation of syariah financial forms and standards' through 'harmonization of fatwa issued by the National Syariah Board with syariah banking regulations. ${ }^{42}$

Selanjutnya, perjanjian (aqad) syariah merupakan suatu perikatan antara ijab dengan qabul, yang dilakukan sesuai syarak dan dapat menimbulkan akibat-akibat hukum pada objeknya. Pengertian ijab adalah pernyataan pihak pertama mengenai isi perikatan yang diinginkan, sedangkan qabul adalah pernyataan

\footnotetext{
42Tim Lindsey, 2012, "Between Piety and Prudence: State Syariah and the Regulation of Islamic Banking in Indonesia", 34 Sydney L. Rev. 107, Sydney Law Review, hlm. 122.
} 
pihak kedua untuk menerimanya. ${ }^{43}$ Lebih lanjut, KH. Ahmad Azhar Basyir mengartikan ijab adalah perkataan orang yang pertama untuk melakukan perjanjian jual beli. Perkataan tersebut berasal dari penjual maupun dari pembeli. Adapun qabul adalah sesuatu yang disebutkan oleh pihak kedua dari perkataan salah seorang yang melakukan perjanjian. Qabul menunjukkan kesepakatan dan kerelaan terhadap sesuatu yang telah diijabkan pada saat di awal (ijab). ${ }^{44}$

\begin{abstract}
Pernyataan kehendak berdasarkan ijab dan qabul merupakan unsur penting di dalam perjanjian. Akan tetapi untuk sahnya suatu perjanjian tidak hanya harus memenuhi ijab dan qabul saja, tetapi harus memenuhi semua rukun dan syarat perjanjian yang telah diatur dalam hukum Islam. Adapun rukunrukun perjanjian tersebut, antara lain adalah ${ }^{45}$ al-'aqidan (para pihak yang melakukan perjanjian), shighatul-'aqd (pernyataan kehendak para pihak),
\end{abstract}

${ }^{43} \mathrm{KH}$. Ahmad Azhar Basyir, 2000, Asasasas Hukum Muamalat (Hukum Perdata Islam), UII Press, Yogyakarta, hlm. 65.

${ }^{44}$ Wahbah az-Zuhaili, 2005, al-Fiqh alIslami wa Adillatuh, Dar al-Fikri, Damaskus, hlm. 2931. mahallul-'aqd (objek perjanjian), dan maudhu' al-'aqd (tujuan perjanjian).

Rukun perjanjian merupakan suatu kesatuan yang utuh, artinya rukun tersebut tidak dapat dipisahkan satu sama lain, sehingga harus dipenuhi secara lengkap (sempurna). Apabila perjanjian hanya memenuhi beberapa unsur atau unsurnya tidak utuh, maka perjanjian itu dianggap tidak memenuhi rukun. Oleh karena itu, perjanjian tersebut dianggap tidak sah atau batal.

Adapun yang harus dipenuhi setelah memenuhi rukun perjanjian adalah syarat-syaratperjanjian.Syaratsyarat perjanjian tersebut di antaranya adalah syarat terbentuknya perjanjian (syuruth al-in'iqad), yaitu ${ }^{46}$ tamyiz, berbilang pihak (atta'adud), persesuaian ijab dan kabul, kesatuan majelis perjanjian. Selain itu, syarat terbentuknya perjanjian yang selanjutnya adalah objek perjanjian dapat diserahkan, objek perjanjian tertentu atau dapat ditentukan, objek perjanjian yang dapat ditransaksikan,

\footnotetext{
${ }^{45}$ Az-Zarqa', dan Wahbah az-Zuhaili, dalam Syamsul Anwar,2007, Hukum Perjanjian Syariah, RajaGrafindo Persada, Jakarta, hlm. 96.

${ }^{46}$ Syamsul Anwar, Ibid.,hlm. 98.
} 
dan tujuan perjanjian tidak yang bertentangan dengan syara'.

$$
\text { Syarat terbentuknya }
$$

perjanjian di atas merupakan pokok (al-ashl). Apabila pokok tersebut tidak terpenuhi, perjanjian tidak dapat terjadi, sehingga perjanjian tidak memiliki wujud yuridis syar'i. ${ }^{47}$ Yuridis syar'i adalah ketentuan-ketentuan yang telah ditentukan berdasarkan hukum Islam. Oleh karena itu, perjanjian yang tidak memiliki wujud syar'i merupakan perjanjian yang tidak seusai dengan ketentuanketentuan dalam Islam, sehingga perjanjian tersebut dapat menyebabkan tidak sah atau batal demi hukum.

$$
\text { Syarat perjanjian yang }
$$
selanjutnya adalah syarat keabsahan perjanjian (syuruth ash-shihhah), yang terdiri dari ${ }^{48}$ bebas dari paksaan, bebas dari gharar, dan bebas dari riba. Selain itu, syarat keabsahan perjanjian adalah bebas dari syarat fasid, dan tidak menimbulkan kerugian ketika melakukan penyerahan.

Terpenuhinya rukun dan syarat terbentuknya perjanjian akan

\footnotetext{
${ }^{47}$ Syamsul Anwar,Ibid., hlm. 99.

48Syamsul Anwar, Ibid.,hlm. 100-101.
}

menyebabkan perjanjian tersebut menimbulkan wujud yuridis syar'i. Perjanjian yang telah memiliki wujud yuridis syar'i masih memerlukan syarat-syarat tambahan sebagai penyempurna, sehingga perjanjian tersebut dapat dikatakan sah secara hukum. Syarat-syarat penyempurna dalam perjanjian tersebut dikatakan sebagai syarat keabsahan perjanjian. ${ }^{49}$ Kemudian, syarat perjanjian yang berikutnya adalah syarat berlakunya akibat hukum (syuruth an$n a f a d z$ ), yang berupa ${ }^{50}$ kewenangan sempurna atas objek perjanjian. Kewenangan tersebut terdiri dari adanya kepemilikan, adanya penguasaan, atau tidak tersangkut dengan hak orang lain. Selain itu, syarat berlakunya akibat hukum yang berikutnya adalah kewenangan sempurna atas tindakan.

Syarat berlakunya akibat hukum merupakan syarat penentu terhadap suatu perjanjian supaya dapat dieksekusi. Artinya, perjanjian sudah dapat dikatakan sah apabila sudah memenuhi rukun dan syarat keabsahan tetapi belum dapat

\footnotetext{
${ }^{49}$ Syamsul Anwar,Ibid., hlm. 99

50Syamsul Anwar, Ibid., hlm. 102-103.
} 
dilaksanakan.Oleh karena itu, syarat tersebut diperlukan.

Perjanjian yang sudah sah serta dapat dilakukan eksekusi dan tidak dapat dilakukan eksekusi dapat dibagi menjadi dua macam yaitu, perjanjian maukuf dan nafiz. ${ }^{51}$ Perjanjian yang sudah sah, tetapi belum dapat dieksekusi dikatakan sebagai perjanjian maukuf (aqad maukuff. Hal tersebut karena belum memenuhi syarat berlakunya akibat hukum.Adapun perjanjian-perjanjian yang sudah sah dan dapat dilakukan eksekusi dikatakan sebagai perjanjian nafiz. Hal tersebut karena perjanjian tersebut telah memiliki syarat berlakunya akibat hukum.

Adapun syarat perjanjian yang terakhir adalah syarat mengikatnya perjanjian (syurthul-lazum). Perjanjian dapat dikatakan mengikat apabila semua syarat dan rukun telah terpenuhi. Akan tetapi, ada sebagian perjanjian yang tidak serta merta mengikat secara hukum karena memiliki sifat tersendiri, yaitu adanya hak khiyar. Hak khiyar adalah hak seseorang atau para pihak yang dapat memilih untuk meneruskan atau membatalkan suatu perjanjian yang dilakukannya.

\section{E. KESIMPULAN}

Di dalam praktik perbankan syariah antara lain mempunyai lima prinsip-prinsip dasar. Di antaranya adalah prinsip titipan atau simpanan (depository/al-wadi'ah), prinsip bagi hasil (profit-sharing), jual beli (sale and purchase), sewa (operational lease and financial lease), dan jasa (fee-based services). Hukum perjanjian menganut beberapa asas. Di antaranya adalah asas kebebasan mengadakan perjanjian (arti otonomi), asas konsensualisme (penyesuaian kehendak), dan asas kepercayaan. Selain itu, ada juga asas kekuatan mengikat, asas persamaan hukum, asas keseimbangan, asas kepastian hukum, asas moral, asas kepatutan, dan asas kebiasaan.

Berdasarkan beberapa asas perjanjian seperti disebut di atas, ada tiga asas yang menjadi tonggak hukum perjanjian dalam hukum perbankan. Ketiga asas tersebut adalah asas konsensualisme, asas kebebasan berkontrak, dan asas kekuatan mengikat. Asas konsensualisme dilahirkan pada saat momentum awal

\footnotetext{
${ }^{51}$ Syamsul Anwar, Ibid., hlm. 103-104.
} 
terjadinya perjanjian, yaitu ketika para pihak mencapai puncak kesepakatannya. Adapun para pihak menentukan hak dan kewajiban serta hal-hal lain yang menjadi substansi perjanjian, mereka telah memasuki ruang asas kebebasan berkontrak. Di dalam asas ini, para pihak dapat menentukan sendiri bentuk dan isi perjanjian secara bebas sepanjang dapat dipertanggungjawabkan. Tekanan dari salah satu pihak melalui ketidaksamaan dalam tawar-menawar (bargaining power) dapat mengakibatkan prestasi perjanjian tidak seimbang dan hal ini melanggar asas iustum pretium. Perjanjian tersebut akan menjadi cacat dan dapat dibatalkan (vernietigbaar, voidable). Adanya persetujuan secara timbal balik terhadap bentuk dan isi perjanjian ditandai dengan adanya pembubuhan tanda tangan atau yang dapat dipersamakan dengan itu. Tanda tangan yang dibubuhkan para pihak menjadi pengakuan yang sah terhadap isi perjanjian. Akibatnya, hal tersebut akan mengikat kedua belah pihak dan mereka harus melaksanakannya dengan itikad baik (in good faith).

\section{DAFTAR PUSTAKA}

Al-Kashif, Abd. El-Rehim Mohamed, 2008,"Islamic institutions offering financial services: the constructive role and implications of their modes for efforts to combat serious financial crime", Comp. Law. 2008, 29(7), 218-224, Company Lawyer.

Anonimus, Himpunan Fatwa Dewan Syariah Nasional Untuk Lembaga Keuangan Syariah.2001, Dewan Syariah Nasional-Majelis Ulama Indonesia dan Bank Indonesia.

1990, Kamus Besar Bahasa Indonesia, Cet. Ketiga, Departemen Pendidikan dan Kebudayaan, Balai Pustaka, Jakarta.

Anshori, Abdul Ghofur, 2006, Gadai Syariah di Indonesia: Implementasi dan Institusionalisasi, Cet. Pertama, Gadjah Mada Press, Yogyakarta.

Antonio, Muhammad Syafi'i, 2001, Bank Syari'ah: Dari Teori ke Praktik, Gema Insani Press, Jakarta.

Anwar, Syamsul,2007, Hukum Perjanjian Syariah, Raja Grafindo Persada, Jakarta.

2006, Bahan Kuliah S3 Ekonomi Islam, UIN Sunan Kalijaga, Yogyakarta.

az-Zuhaili, Wahbah, 2005, al-Fiqh alIslami wa Adillatuh, Dar al-Fikri, Damaskus.

Badrulzaman,Mariam Darus, 2001, KUHPerdata, Buku III, Hukum Perikatan dengan Penjelasan, Alumni, Bandung.

Basyir, KH. Ahmad Azhar, 2000, Asasasas Hukum Muamalat (Hukum Perdata Islam), UII Press, Yogyakarta 
Dhumale, Rahul dan Amela Sapcanin dalam Betsy Walters, 2012, "Islamic Microfinance: Sustainable Poverty Alleviation for the Muslim Poor", 11 Conn. Pub. Int. L.J. 255, Connecticut Public Interest Law Journal.

Djamil, Fathurrahman, 2002,"Urgensi Undang-Undang Perbankan Syari'ah di Indonesia", Jurnal Hukum Bisnis, Vol 20, AgustusSeptember, Yayasan Pengembangan Hukum Bisnis, Jakarta.

Istanto, F. Sugeng, 2007, Penelitian Hukum, Ganda, Yogyakarta.

Kamello, Tan, 2006, "Karakter Hukum Perdata dalam Fungsi Perbankan melalui Hubungan antara Bank dengan Nasabah", Pidato Pengukuhan Jabatan Guru Besar Tetap dalam Bidang Ilmu Hukum Perdata, Fakultas Hukum, Universitas Sumatera Utara.

Kepli, Mohd Yazid Bin Zul, 2012, "Islamic Finance in Hong Kong", 42 HKLJ 809, Hong Kong Law Journal.

Khalil, Jafril, 2002, "Prinsip Syari'ah dalam Perbankan", Jurnal Hukum Bisnis, Vol 20, Agustus-September, Yayasan Pengembangan Hukum Bisnis, Jakarta.

Lindsey, Tim, 2012, "Between Piety and Prudence: State Syariah and the Regulation of Islamic Banking in Indonesia", 34 Sydney L. Rev. 107, Sydney Law Review.

Lubis, Suhrawardi K, 2000, Hukum Ekonomi Islam,Sinar Grafika, Jakarta.

Mardjono, 2000, Petunjuk Praktis: Menjalankan Syari'at Islam dalam Bermuamalah yang Sah Menurut Hukum Islam, Dewan Pimpinan Pusat Bulan Bintang, Jakarta.
Mertokusumo, Sudikno, 2001, Penemuan Hukum; Sebuah Pengantar, Liberty, Yogyakarta.

-----, 2001, Penemuan Hukum;
Yogyakarta.

Sihombing, Jonker, 2008, Tanggung Jawab Yuridis Bankir atas Kredit Macet Nasabah, Alumni, Bandung.

Soekanto, Soerjono, 2007, Pengantar Penelitian Hukum, Universitas Indonesia Press, Jakarta.

Soekanto, Soerjono dan Sri Mamudji, 1995, Penelitian Hukum Normatif: Suatu Tinjauan Singkat, Raja Grafindo Persada, Jakarta.

Tabari, Nima Mersadi, 2010, "Islamic Finance and The Modern World: The Legal Principles Governing Islamic Finance in International Trade", Company Lawyer, Comp. Law.31(8), 249-254.

Taylor, J. Michael, 2003, "Islamic Banking-The Feasibility of Establishing an Islamic Bank in The United States", American Business Law Journal, 40 Am. Bus. L.J. 385, Winter.

Umam, Khotibul, 2009, Hukum Ekonomi Islam; Dinamika dan Perkembangan di Indonesia, Instan Lib, Yogyakarta. 